\title{
Çeşitli Yörelerimizde Üretilen Çiçek Ballarının Fizikokimyasal Özelliklerinin Belirlenmesi ve Türk Gıda Kodeksi'ne Uygunluğunun Değerlendirilmesi
}

\author{
Mine Gültekin-Özgüven ${ }^{1 *}$, Evren Demircan ${ }^{2}$, Beraat Özçelik ${ }^{3}$ \\ 1* İstanbul Teknik Üniversitesi, Kimya-Metalurji Fakültesi, Gıda Mühendisliği Bölümü, İstanbul, Türkiye (ORCID: 0000-0002-2073-8075), gultekinmi@itu.edu.tr \\ 2 İstanbul Teknik Üniversitesi, Kimya-Metalurji Fakültesi, Gıda Mühendisliği Bölümü, İstanbul, Türkiye (ORCID: 0000-0001-8533-6037), evrendemircan@itu.edu.tr \\ ${ }^{3}$ İstanbul Teknik Üniversitesi, Kimya-Metalurji Fakültesi, Gıda Mühendisliği Bölümü, İstanbul, Türkiye (ORCID: 0000-0002-1810-8154), ozcelik@itu.edu.tr
}

(Illk Geliş Tarihi 26 Haziran 2020 ve Kabul Tarihi 13 Eylül 2020)

(DOI: $10.31590 /$ ejosat.758399)

ATIF/REFERENCE: Gültekin-Özgüven, M., Demircan E. \& Özçelik B. (2020). Çeşitli Yörelerimizde Üretilen Çiçek Ballarının Fizikokimyasal Özelliklerinin Belirlenmesi ve Türk Gıda Kodeksi'ne Uygunluğunun Değerlendirilmesi. Avrupa Bilim ve Teknoloji Dergisi, (20), 321-326.

$\ddot{O} \mathbf{z}$

Bal, bal arıları (Apis mellifera) tarafından üretilen tatlı ve doğal bir gıdadır. Son derece besleyici, enerji verici ve terapötik özellikleri olan balın kalitesi ticari değerini de etkileyen botanik ve coğrafi kökenine bağlıdır. Diğer taraftan, bal taklit ve tağşiş yapılarak tüketicinin aldatılmasına uygun bir gıda maddesidir. Bu nedenlerle, ulusal ve uluslar arası gıda kodekslerinde balın kalitesini, botanik kaynağını ve saflığını belirlemek için çeşitli parametreler ve analiz yöntemleri tanımlanmıştır. Bu kapsamda tanımlanan parametrelerden olan balın fizikokimyasal özelliklerinin belirlenmesi hedeflenmiştir. $\mathrm{Bu}$ çalışmada; çeşitli yörelerdeki bal üreticilerinden temin edilen bir tanesi kestane balı olmak üzere toplam on iki adet çiçek balı numunesinin kalitesinin değerlendirilmesi, botanik kökeninin belirlenmesi ve Türk Gıda Kodeksi (TGK)'ne uygunluğununun değerlendirilmesi amaçlanmıştır. Bal numunelerinin nem, elektrik iletkenliği, indirgen ve indirgen olmayan şeker içeriği, ticari glikoz varlıği, hidroksi metil furfural (HMF) miktarı, diastaz aktivitesi, serbest asitlik, prolin miktarı ve suda çözünmeyen katı madde miktarı analizleri gerçekleştirilmiştir. Elde edilen verilere göre, toplam on iki çiçek balı örneğinden yedi tanesinin TGK'ye uygun bulunduğu anlaşılmıştır. Bal numunelerinin hiç birinde ticari glikoz varlığ tespit edilmemiştir. Numunelerin düşük HMF içeriği ve en az 9 olarak tespit edilen diastaz aktivitesi balların uygun depolama koşullarında tutulduğunun göstergesidir. Beklendiği gibi unifloral bir çiçek balı olan kestane balının elektrik iletkenliği ve fruktoz/glikoz oranı diğer multifloral çiçek ballarından farklı bulunmuştur. Son olarak, söz konusu fizikokimyasal özelliklerin coğrafi köken tespitinde kullanılma potansiyelleri değerlendirilmiş ve özellikle nem içeriğinin coğrafi köken tespitinde kullanılabileceği öngörülmüştür. Fizikokimyasal özelliklerin coğrafi köken tespitinde kullanılıp kullanılmayacağının değerlendirilmesi için çok sayıda numune ile çalışmak gerekliliği anlaşılmıştır.

Anahtar Kelimeler: Bal, Fizikokimyasal Özellikler, Botanik Köken, Türk Gıda Kodeksi.

\section{Determination of Physicochemical Properties of Flower Honeys Produced in Various Locations and Their Compliance with the Turkish Food Codex}

\begin{abstract}
Honey is a sweet and natural food produced by Apis mellifera bees. The quality of honey, which is highly nutritious, energizing and therapeutic, depends on its botanical and geographical origin, which also affects its commercial value. On the other hand, honey is a food suitable for deceiving the consumer by imitation and adulteration. For these reasons, various parameters and related methods of analysis have been defined to determine the quality, botanical source and purity of honey in national and international food codexes. It is aimed to determine the physicochemical properties of honey, which is one of the parameters defined in this context. In this study; it is aimed to evaluate the quality of twelve flower honey samples, one of which is chestnut honey, obtained from honey producers in various regions, to determine their botanical origin and to evaluate their compliance with the Turkish Food Codex (TGK). Analysis of
\end{abstract}

* Sorumlu Yazar: gultekinmi@itu.edu.tr 
moisture, electrical conductivity, reducing and non-reducing sugar content, presence of commercial glucose, amount of hydroxy methyl furfural (HMF), diastase activity, free acidity, proline and water insoluble solids were carried out. According to the data obtained, it was understood that seven of the twelve flower honey samples were suitable for TGK. The presence of commercial glucose was not detected in any of the honey samples. The low HMF content of the samples and the diastase activity determined to be at least 9 were indications that the honey was kept under appropriate storage conditions. As expected, the electric conductivity and fructose / glucose ratio of chestnut honey, which is an unifloral flower honey was found different from other multifloral flower honeys. Finally, the potentials of using these physicochemical properties in geographical origin determination were evaluated and it was envisaged that moisture content could be used in geographical origin determination. It has been understood that it is necessary to work with a large number of samples to evaluate whether the physicochemical properties will be used for geographical origin determination.

Keywords: Honey, Physicochemical Properties, Botanical Origin, Turkish Food Legistlation.

\section{Giriş}

Türkiye sahip olduğu bitki ve arı ırkı çeşitliliği sayesinde dünyada kovan sayısı ve bal üretimi itibariyle ikinci sırada yer almaktadır. Nitekim bal Türk mutfağı'nda özellikle kahvaltı sofralarında sıklıkla yer almaktadır. Bilinen ilk doğal tatlandırıcıdır. Türk Gıda Kodeksi Bal Tebliği'ne (2020/7) göre bal, "bitki nektarlarının, bitkilerin canlı kısımlarının salgılarının veya bitkilerin canlı kısımları üzerinde yaşayan bitki emici böceklerin salgılarının, bal arısı tarafından toplandıktan sonra kendine özgü maddelerle birleştirerek değişikliğe uğrattığı, su içeriğini düşürdüğü ve petekte depolayarak olgunlaştırdığı, doğas1 gereği kristallenebilen doğal üründür" olarak tanımlanmıştır. Yine TGK'de botanik kaynağına göre ballar çiçek ve salgı balı olmak üzere iki gruba ayrılmıştır. Çiçek balları ait olduğu botanik kaynağın duyusal, fiziksel, kimyasal ve palinolojik özelliklerini belirgin olarak taşıdığında söz konusu ballar monofloral veya unifloral olarak adlandırılırlar. Kestane, ıhlamur, kekik vb ballar monofloral ballardır. Kaynağı belirgin olmayan çiçek balları ise multifloral olarak değerlendirilmektedir.

Balın kompozisyonu bitki çeşidine, iklime, çevre koşullarına, coğrafyaya ve arı yetiştiricisinin uygulamalarına göre değişkenlik göstermekle birlikte (Küçük ve diğ., 2007) \%65'i glikoz ve fruktoztan oluşmakta olup, \%18'i su, geri kalanı protein ve lipidleri (Aloglu ve diğ., 2017) içermektedir. Ayrıca, balda mineral ve ağır metaller de mevcuttur (Aloglu ve diğ., 2017). İçeriğinin büyük bir kısmı şeker olmasına rağmen bal sadece şekerden ibaret olmayıp sahip olduğu besleyici ve tıbbi özellikleri nedeniyle oldukça değerli bir üründür. İçerdiği fenolik asitler, flavonoidler, antosiyaninler, prosiyanidinler gibi polifenol yapısındaki biyoaktif bileşenler sayesinde antioksidan, antitümör, antibakteriyel ve anti-enflamatuar özellikler göstermektedir (Can ve diğ., 2015). Nitekim, eski Misır ve Yunan kültürlerinden beri (Aloglu ve diğ., 2017) astım (Küçük ve diğ., 2007), gastrointestinal sistem hastalıkları, kardiyovasküler hastalıklar ile çeşitli oftalmolojik durumların tedavisinde ve yaraların iyileştirilmesinde (Kolayli ve di $\breve{g}, 2016$ ) kullanıldığı bilinmektedir.

Balın kalitesi duyusal, kimyasal, fiziksel ve mikrobiyolojik özelliklerine göre belirlenmektedir. Özellikle, balın fizikokimyasal özelliklerinin belirlenmesi balın kalitesi ve botanik kaynağını belirleyen sertifikasyon süreci için çok önemlidir. $\mathrm{Bu}$ özelliklerden bazıları; hidroksimetilfurfural içeriği, diastaz aktivitesi, nem içeriği, asitlik derecesi, indirgen ve indirgen olmayan şeker içeriği, elektrik iletkenliği (Kekecoglu ve Rasgele, 2013) ve prolin miktarıdır. Balın coğrafi kaynağının belirlenmesi içinse gaz kromatografisi-kütle spektroskopisi (aromatik bileşenler), elektronik burun teknolojisi (uçucu bileşenler) (Huang ve diğ., 2015; Solayman ve diğ., 2016), yüksek performanslı sıvı kromatografisi (flavonoidler, amino asitler, şekerler, fenolik asitler), yakın infrared (NIR) ve Raman spektroskopisi (kontaminasyon) gibi yöntemler kullanılmaktadır (Aloglu ve diğ., 2017). Ancak, bu yöntemler pahalı ve uzmanlık isteyen analizlerdir. $\mathrm{Bu}$ nedenle nisbeten daha ulaşılabilir ve ekonomik olan fizikokimyasal özelliklerin balın coğrafi olarak işaretlenmesinde bu yöntemlere ne kadar katkı sağlayabileceği üzerine araştırmalar devam etmektedir. Bu kapsamda, nem, asitlik ve pH, HMF, elektriksel iletkenlik özelliklerinin balın coğrafi kökenin tespit edilmesinde yardımcı parametreler olabileceği daha önce bazı araştırıcılar tarafından rapor edilmiştir (Fechne ve diğ., 2016; Karabagias ve diğ., 2014).

Tüm bu bilgilerden yola çıkılarak bu çalışmada, farklı yörelerimizdeki bal üreticilerden elde edilen birisi monofloral çiçek balı (kestane balı), on biri multifloral olmak üzere toplam on iki adet çiçek balının kalitesini belirleyebilmek ve TGK'ne uygunluğunun değerlendirilmesi için örneklerin şeker içeriği, ticari glikoz varlığı, nem içeriği, suda çözünmeyen katı madde miktarı, elektriksel iletkenliği, serbest asitlik derecesi, diastaz sayısı, prolin ve HMF miktarı gibi fizikokimyasal özellikleri belirlenmiştir. Ayrıca, bu fizikokimyasal özelliklerin balın coğrafi kökeninin belirlenmesinde kullanılıp kullanılmayacağının ön değerlendirilmesi yapılmıştır.

\section{Materyal ve Metot}

\subsection{Materyal}

$\mathrm{Bu}$ çalışmada çeşitli arı yetiştiricileriyle temasa geçilerek üreticilerden temin edilen farklı yörelere ait bir adedi kestane balı olmak üzere toplam on iki adet çiçek balı analizlenmiştir. Kullanılan tüm kimyasallar Sigma-Aldrich marka olup analitik saflıktadır.

\subsection{Metot}

\subsubsection{Nem İçeriğinin Belirlenmesi}

Bal numunelerinin nem içeriği Abbe refraktometresinden yararlanılarak TS $13365^{\prime}$ 'e göre ölçülmüştür. Ölçümler $25^{\circ} \mathrm{C}$ 'de yapılmıştır. Sonuçlar balın su içeriği refraktif indeksle arasındaki ilişkiye göre hesaplanmış ve $\mathrm{g} / 100 \mathrm{~g}$ olarak ifade edilmiştir.

\subsubsection{Elektrik İletkenliğin Ölçülmesi}

Bal numunelerinin elektrik iletkenliği bir kondüktometre yardımıyla IHC (International Honey Commission-Uluslararası Bal Komisyonu)'nin önerdiği şekilde ölçülmüştür. Sonuçlar $\mathrm{mS} / \mathrm{cm}$ olarak ifade edilmiştir.

\subsection{3. Şeker Profilinin HPLC ile Belirlenmesi}


Bal numunelerinin şeker içeriği refraktif indeks dedektörü (RID) ve Inertsil marka NH2 şeker kolonu (3 $\mu \mathrm{m}$ partikül boyutu, $25 \mathrm{~cm} \times 4.6 \mathrm{~mm}$ ) ekipmanına sahip ters faz HPLC ile AOAC 977.20'de tarif edildiği gibi belirlenmiştir. Kısaca 5 gr bal numunesi $25 \mathrm{ml}$ suda çözündürüldükten sonra üzerine $25 \mathrm{ml}$ asetonitril eklenerek iyice karıştırılır. Karışımlar $0.45 \mu$ m'lik filtrelerden geçirilerek viallere aktarılır. Mobil faz olarak \%83 asetonitril ve $\% 17$ su karışımı kullanılarak, analiz 23 dakikalık izokratik akışla gerçekleştirilmiştir. İnjeksiyon hacmi $10 \mu \mathrm{L}$ ve toplam akış hızı $1 \mathrm{ml} / \mathrm{dk}$ 'dır. Bal örneklerindeki şeker içeriğinin tanımlanması ve miktarının tayini için fruktoz (3.804 g), glikoz $(3.010 \mathrm{~g})$ ve sakkaroz $(0.602 \mathrm{~g})$ standartları ile hazırlanan şeker karışımı kullanılmıştır. Hazırlanan standart kalibrasyon grafiğine göre sonuçlar $\mathrm{g} / 100 \mathrm{~g}$ cinsinden verilmiştir.

\subsubsection{Ticari Glikoz Varlı̆̆ının Tespit Edilmesi}

Bal numunelerindeki ticari glikoz varlığının tespiti TS 3036'ya göre iyot metodu ile kalitatif olarak gerçekleştirilmiştir.

\subsubsection{Hidroksimetilfurfural Miktarının HPLC ile Belirlenmesi}

Bal numunelerinin HMF miktarının tayini PDA dedektörü ve Phenomenex marka C18 kolonu ( $5 \mu \mathrm{m}$ partikül boyutu, 15 cm x $4.6 \mathrm{~mm}$ ) ekipmanlı ters faz HPLC ile TS 13356'de tarif edildiği gibi belirlenmiştir. Mobil faz; \% 85'lik (v/v) ve \% 10 'luk (v/v) ortofosforik asit çözeltileri kullanılarak $\mathrm{pH}$ değeri 3'e ayarlanmış disodyum hidrojenfosfat çözeltisi ve metanol (95:5, v/v) karışımını içermektedir. Akış hızı 1ml/dk, injeksiyon hacmi $10 \mu$ l'dir. Çalışılan dalga boyu $284 \mathrm{~nm}$ 'dir. İzokratik akışla 17 dakikada kromatografik ayrışma sağlanmıştır. Sonuçlar HMF standardı kullanılarak hazırlanan standart kalibrasyon grafiğgine göre $\mathrm{mg} / \mathrm{kg}$ cinsinden hesaplanmıştır.

\subsubsection{Diastaz Sayısının Belirlenmesi}

Diastaz aktivitesi baldaki amilaz enzimlerinin $1 \mathrm{~g}$ balda 1 saat içinde parçaladığı \%1'lik nişasta çözeltisinin mililitre cinsinden miktarın ifade etmektedir. Bal numunelerinin diastaz aktivitesi TS 13364 'e göre $40{ }^{\circ} \mathrm{C}$ 'de tayin edilmiştir. Absopsiyon UV/VIS spektrofotometre ve bir kronometre ile takip edilmiştir.

\subsubsection{Serbest Asitlik Tayini}

Bal numunelerinin asitliği TS 13360 'da tarif edildiği gibi titrimetrik yöntemle ve bir pH-metre yardımıyla yapılmıştır. Titrasyon $8.3 \mathrm{pH}$ 'de kesilmiştir. Sonuçlar meq/kg cinsinden ifade edilmiştir.

\subsubsection{Prolin Tayini}

Bal numunelerinin prolin miktarı AOAC 979.20'ye göre spektrofotometerik yöntemle gerçekleştirilmiş olup hesaplamalar prolin standardı kullanılarak oluşturulan kalibrasyon grafiğine göre $\mathrm{mg} / \mathrm{kg}$ cinsinden hesaplanmıştır.

\subsubsection{Suda Çözünmeyen Katı Madde Miktarının Belirlenmesi}

Bal numunelerinin suda çözünmeyen katı madde miktarı TS 3036'ya göre gravimetrik yöntemle gerçekleştirilmiştir. Sonuçlar $\%$ cinsinden ifade edilmiştir.

\subsubsection{0. İstatistiksel Analiz}

İstatistiksel analizler IBM SPSS software (21.0, Chicago, IL, USA) kullanılarak gerçekleştirilmiştir. Tüm analizler en az 3 kere tekrarlanmıştır. Sonuçlar ortalama değerler ve standart e-ISSN: 2148-2683 sapma değerleri ile birlikte verilmiştir. Farklılıklar Tukey testi ile $\mathrm{P}$ değeri $<0.05$ 'e göre değerlendirilmiştir.

\section{Araştırma Sonuçları ve Tartışma}

Balın fizikokimyasal özellikleri için TGK Bal Tebliği’nde izin verilen referans değerleri Tablo 1'de verilmiştir. Buna göre kestane balının elektrik iletkenliği ve fruktoz/glikoz oranı multifloral çiçek ballarından farklılık göstermektedir. $\mathrm{Bu}$ değerler eğik gösterilmiştir.

Bal numunelerinin belirlenen fizikokimyasal özelliklerine ait sonuçlar ise Tablo 2'de gösterilmiştir. Referans değerlerinden yüksek veya düşük çıkan uygun olmayan analiz sonuçları koyu renkle gösterilmiştir.

Yüksek nem içeriği balın raf ömrünün kısalmasına, artan maya faaliyeti ile bunun sonucunda fermentasyonun başlamasına ve kristallenmenin başlamasına sebep olabilmektedir. Tablo 2'de görüldüğü gibi analiz edilen bal numunelerinin nem içerikleri \% 16.4-19.9 arasında değişmekte olup TGK'de izin verilen azami değer olan \%20 sınırını aşmamıştır. Nem içeriği karşılaştırıldığında tüm numuneler arasında istatistiksel olarak anlamlı farklar olduğu görülmektedir $(\mathrm{p}<0.05)$. Birbirine yakın yörelerden (Çankırı, Kastamonu ve Tokat) gönderilen örneklerin nem içeriklerinin birbirine daha yakın olduğu görülmüştür. Nitekim, Fechner ve diğ. (2016) ve Karabagias ve diğ. (2014) nem parametresinin balların coğrafi kökenlerinin belirlenmesinde kullanılabilecek fizikokimyasal özelliklerden biri olduğunu bildirmiştir. Buradan yola çıkarak nem içeriğinin coğrafi kökenin belirlenmesinde kullanilabileceği sonucuna varılabilmekle birlikte tek başına yeterli değildir.

Tablo 1. TGK'ye Göre Çiçek Balın Fizikokimyasal Özelliklerinin Referans Değerleri ve Atıfta Bulunulan Ulusal ve Uluslar Arast Gıda Kodeksleri

\begin{tabular}{|c|c|c|c|}
\hline Analiz & $\begin{array}{l}\text { Minimum } \\
\text { değer }\end{array}$ & $\begin{array}{l}\text { Maksimum } \\
\text { değer }\end{array}$ & $\begin{array}{c}\text { Gida } \\
\text { Kodeksi* }\end{array}$ \\
\hline & \multicolumn{2}{|c|}{ Çiçek Balı } & \\
\hline Rutubet (\%) & - & 20 & TS 13365 \\
\hline $\begin{array}{l}\text { **Elektrik } \\
\text { İletkenliği } \\
(\mathrm{mS} / \mathrm{cm})\end{array}$ & - & $\begin{array}{c}0.8 \\
-\end{array}$ & $\mathrm{IHC}$ \\
\hline $\begin{array}{l}\text { Ticari Glikoz } \\
\text { Varlığ } 1\end{array}$ & \multicolumn{2}{|c|}{ Bulunmamalı } & TS3036 \\
\hline Sakkaroz (\%) & - & 5 & $\begin{array}{l}\text { AOAC } \\
977.20\end{array}$ \\
\hline $\begin{array}{l}* * \text { Fruktoz / } \\
\text { Glikoz }\end{array}$ & $\begin{array}{c}0.9 \\
1\end{array}$ & $\begin{array}{l}1.4 \\
1.85\end{array}$ & $\begin{array}{l}\text { AOAC } \\
977.20\end{array}$ \\
\hline $\begin{array}{l}\text { Fruktoz+Glikoz } \\
(\%)\end{array}$ & 60 & - & $\begin{array}{l}\text { AOAC } \\
977.20\end{array}$ \\
\hline $\mathrm{HMF}(\mathrm{mg} / \mathrm{kg})$ & - & 40 & TS 13356 \\
\hline $\begin{array}{l}\text { Suda } \\
\text { Çözünmeyen Katı } \\
\text { Madde Miktarı } \\
(\%)\end{array}$ & - & 0.1 & TS 3036 \\
\hline Asitlik (meq/kg) & - & 50 & TS 13360 \\
\hline Diastaz Sayısı & 8 & - & TS 13364 \\
\hline Prolin (mg/kg) & 300 & - & $\begin{array}{l}\text { AOAC } \\
979.20\end{array}$ \\
\hline
\end{tabular}

*IHC: International Honey Commission, AOAC: The Association of Official Analytical Chemists, TS: Türk Standardı 
**: Üstte verilen değerler çiçek balları için, altta verilen ve eğik gösterilen değerler kestane balı içindir.

Elektriksel iletkenlik özelliğinden çiçek ve salgı ballarının birbirinden ayırt edilmesinde yararlanılmaktadır. Elektriksel iletkenlik kül, organik asitler, proteinler, iyonlar ve bazı kompleks şekerlere bağlıdır ve botanik kökene göre değişiklik göstermektedir. $\mathrm{Bu}$ nedenle unifloral balların karakterizasyonunda önemlidir. 0 ile $0.8 \mathrm{mS} / \mathrm{cm}$ arasında ölçülen elektriksel iletkenlik değeri balın çiçek nektarı ve salgı karışımı olmadığını göstermektedir (Belay ve diğ., 2013). Örneklerin elektriksel iletkenlikleri ölçüldüğünde $1(0.91 \mathrm{mS} / \mathrm{cm})$ ve $2(1.05$ $\mathrm{mS} / \mathrm{cm}$ ) numaralı bal numunelerinin en fazla izin verilen 0.8 $\mathrm{mS} / \mathrm{cm}$ değerini aştıkları anlaşılmaktadır. Diğer çiçek ballarının elektriksel iletkenliklerinin ise $0.18-0.72 \mathrm{mS} / \mathrm{cm}$ aralığında değiştiği görülmektedir. Kestane ballarında bu değer en az 0.8 $\mathrm{mS} / \mathrm{cm}$ olmalı iken 5 numaralı kestane balının bu değeri 1.97 $\mathrm{mS} / \mathrm{cm}$ olup TGK'ye uygundur. Silici (2018) Zonguldak, Bursa ve Yalova'dan temin ettiği kestane ballarının elektrik iletkenliğini ortalama $0.89 \pm 0.36 \mathrm{mS} / \mathrm{cm}$ olarak rapor etmiştir. Örnekler kendi aralarında incelendiğinde beklendiği gibi 5 numaralı kestane balının diğer tüm ballardan istatistiksel olarak $(\mathrm{p}<0.05)$ farklı olduğu görülmekle birlikte 10,12 ve 8 numaralı örneklerin birbirlerine benzer oldukları söylenebilmektedir $(\mathrm{p}>0.05)$. Ayrıca, 4 ve 11 numaralı örnekler de birbirine benzerdir $(\mathrm{p}>0.05)$.

Örnekler ticari glikoz varlığı açısından incelendiğinde sevindirici olarak hiçbir bal numunesinde ticari glikoz tespit edilmemiştir. Bala ticari glikoz veya nişasta katılarak yapılan tağşiş balın besin değerini düşürdüğü gibi insan sağlığını da tehlikeye sokmaktadır (Karadal, 2012). Bu nedenle, balın şeker içeriğinin belirlenmesi uluslararası gıda kodekslerinde (TSE, IHC, CEU vs.) tanımlanan balın saflık kriterlerinden birisidir (Can ve diğ., 2015). Balın indirgen ve ingirgen olmayan şeker içeriği araştırıldığında, numunelerin sakkaroz miktarı \%0-2.88 arasında değişmekte olup izin verilen üst sınır değeri olan $\% 5$ aşılmamıştır. Sakkaroz miktarının yüksek olması arıların arı yetiştiricileri tarafindan fazlaca şekerle beslendiği veya balın erken hasat edildiği anlamına gelebilmektedir. Fruktozun glikoza oranı ise 1.20-1.49 arasında değişmiştir. Çiçek balları için bu oran en fazla 1.4 olabilirken kestane balı için en fazla 1.85 olabilmektedir. Yalnız 8 numaralı numunede bu değer 1.43 olarak tespit edilmiştir. Glikozun suda çözünürlüğü fruktozdan daha az olduğu için fruktoz/glikoz oranından balın kristalizasyonunu değerlendirmede yararlanılmaktadır ve bu oran daha çok nektarın kaynağına bağlıdır (Habib ve diğ., 2014). Nitekim, kestane balının kolay kristallenmediği bilinmektedir (Kolayli ve diğ., 2016). Glikoz ve fruktoz toplamına oransal olarak bakıldığında ise en az \%60 olması gerekli olan bu değerin 2 ve 3 numaralı çiçek ballarında sırasıyla \%56.31 ve \%59.58'de kaldığı görülmektedir. İstatistiksel olaraksa 5 numaralı kestane balının fruktoz/glikoz oranlarının diğer tüm numunelerden farklı olduğu anlaşılmaktadır.

Balın fermente veya kristalize olmasını engellemek için bala 1sıl işlem uygulanmaktadır. Uygulanan bu işlemin çok yüksek sıcaklıklarda yapılması ve/veya balın uygun olmayan koşullarda uzun süre muhafaza edilmesi sonucu HMF oluşumu kaçınılmazdır. HMF, ısıl işlem sonucu indirgen şekerlerle aminoasitler arasında oluşan Maillard reaksiyonu sonucu oluşan bir ara üründür ve gıdalarda oluşumu istenmemektedir. Balda yüksek miktarda HMF oluşumu, renkte esmerleşme, tat ve koku değişi ile besleyici özelliklerinde azalmayı göstermektedir. HMF değerinin çok yüksek çıkması ise bala invert şeker katılarak tağşiş yapıldığının göstergesidir. Normal koşullarda taze balda
HMF bulunmamaktadır. Tablo 2'ye göre bal numunelerinin HMF içeriği $<0.1$ ile $1.22 \mathrm{mg} / \mathrm{kg}$ arasında değişmektedir ki bu değer TGK'de izin verilen $40 \mathrm{mg} / \mathrm{kg}$ değerinin çok altındadır. HMF oluşumunun tespit edilmesi, diastaz aktivitesi ile birlikte balın tazeliği hakkında bilgi vermektedir (Küçük ve diğ., 2007). Tüm örneklerin HMF içerikleri oldukça düşük çıkmıştır. Ayrıca, literatürde HMF içeriği genellikle spektrofotometrik yöntemlerle tespit edilmektedir. $\mathrm{Bu}$ çalışmada daha hassas sonuç elde edilmesi açısından kromatografik yöntem tercih edilmiştir.

Bal az miktarda enzimler içermektedir ve bu enzimler bala bal arılarının salgılarından geçmektedir. $\mathrm{Bu}$ enzimlerden birisi olan diastaz enzimi alfa ve beta amilaz enzimlerini kapsamaktadır (Küçük ve diğ., 2007). Diastaz aktivitesi balın yüksek 1sıl işleme veya uygun olmayan muhafaza koşullarına maruz bırakılıp bırakılmadığının anlaşılmasında bir göstergedir (Silva, Videira, Monteiro, Valentão, \& Andrade, 2009) çünkü bu enzimin miktarı 1sıl işlem uygulaması veya uygun olmayan muhafaza koşullarında azalmaktadır. Tablo 2'ye göre bal numunelerinin diastaz sayısı 9.0-25.4 arasında değişmektedir ve TGK'de belirtilen en az 8 olmalı koşuluna uygundur. Turgay (2009) Kahramanmaraş yöresinden temin ettiği farklı bal numunelerinin diastaz aktivitesini 8.0-17.6 arasında bulmuştur. Diastaz aktivitesi açısından numuneler istatistiksel olarak karşılaştırıldığında 7 numaralı ve 9 numaralı örnekler birbirlerinden farklıdır $(\mathrm{p}<0.05)$. Diğer örnekler arasında benzerlikler bulunmaktadır.

Bal her ne kadar şekerce zengin tatlı bir gıda ürünü olsa da asidik (pH 3.5-5.5) karakteri nedeniyle aşırı tatlı bir lezzet vermemektedir (Karadal, 2012). Balın asiditesi organik asitlerin özellikle glukonik asit, laktonları veya esterleri ile fosfat ve klorür gibi inorganik iyonların varlığından kaynaklanmaktadır. Ancak, asitliğin yükselmesi balda başlayan fermentasyonun göstergesi olabilmektedir. Ayrıca, unifloral balların otantifikasyonu ve nektar ballarının salg1 ballarından ayırt edilmesine yardımcıdır (Belay ve diğ., 2013). TGK'ye göre balın asitliği en fazla $50 \mathrm{meq} / \mathrm{kg}$ olabilmektedir. Tablo 2'ye göre bal numunelerinin bu değeri aşmadığı ve $18.1-39.6 \mathrm{meq} / \mathrm{kg}$ aralığında kaldığı anlaşılmaktadır. Bal örnekleri istatistiksel olarak kıyaslandığında 1 ve 3 numaralı Tekirdağ yöresinden elde edilen balların asitliğinin diğerlerinden farklı olduğu, diğer ballar arasında benzerlikler olduğu görülmüştür.

Balda 20 adet aminoasit bulunmaktadır. Bunların içinde prolin dominant olarak bulunan aminoasittir ve sahte balda hemen hemen hiç bulunmamaktadır. $\mathrm{Bu}$ nedenle balın prolin miktarının yüksek olması istenmektedir (Can ve diğ., 2015). Bal numunelerinin prolin miktarı 271.0-928.2 mg/kg arasında değişmektedir. TGK'ye göre balda olması gereken minimum miktar $300 \mathrm{mg} / \mathrm{kg}$ iken 10 numaralı balın prolin miktarı 271.0 $\mathrm{mg} / \mathrm{kg}$ 'de kalmıştır ve oldukça düşüktür. Bunun dışındaki tüm bal numunelerin sonucu uygun bulunmuştur. Erez ve diğg. (2015) Siit-Pervari yöresinden elde ettikleri çiçek ballarının prolin miktarını 192-234 mg/kg olarak rapor etmişlerdir. Bununla birlikte istatistiksel olarak 10 ve 11 numaralı örneklerin diğerlerinden ve birbirlerinden farklı olduğu $(\mathrm{p}<0.05)$, diğerleri arasında benzerlikler olduğu söylenebilmektedir.

Balda bulunabilecek suda çözünmeyen katı madde ise mum, polen, bal peteği kalıntıları ve kirlilik göstergesi olarak değerlendirilmektedir (Belay ve diğ., 2013). Bu nedenle suda çözünmeyen katı madde tayini baldaki safsızlıkları göstermektedir ve tüm bal numuneleri için \%0.1'in altında kalmıştır, aynı zamanda TGK'ye uygundur. Ayrıca istatistiksel olarak örnekler arasında fark olmadığı görülmüştür ( $\mathrm{p}>0.05)$. 
European Journal of Science and Technology

Tablo 2.Balın Fizikokimyasal Özellikleri.

\begin{tabular}{|c|c|c|c|c|c|c|c|c|c|c|c|c|}
\hline & $\begin{array}{l}\text { Bal } \\
\text { Tipi }\end{array}$ & $\begin{array}{l}\text { Balın } \\
\text { Orijini }\end{array}$ & $\begin{array}{c}\text { Nem } \\
(\%)\end{array}$ & $\begin{array}{c}\text { Elektrik } \\
\text { İletkenliği } \\
\text { mS/cm }\end{array}$ & $\begin{array}{c}\text { Sakkaroz } \\
(\%)\end{array}$ & $\begin{array}{c}\text { Fruktoz/ } \\
\text { Glikoz }\end{array}$ & $\begin{array}{c}\text { Fruktoz+ } \\
\text { Glikoz }(\%)\end{array}$ & $\begin{array}{c}\text { HMF } \\
(\mathrm{mg} / \mathrm{kg})\end{array}$ & $\begin{array}{c}\text { Suda } \\
\text { Çözünmeyen } \\
\text { Katı Madde } \\
(\%) \\
\end{array}$ & $\begin{array}{c}\text { Asitlik } \\
\text { (meq/kg) }\end{array}$ & $\begin{array}{c}\text { Diastaz } \\
\text { Sayısı }\end{array}$ & $\begin{array}{l}\text { Prolin } \\
\text { (mg/kg) }\end{array}$ \\
\hline 1 & Çiçek & Tekirdağ & $18.2 \pm 0.1^{\mathrm{C}}$ & $\begin{array}{l}0.91 \pm 0.00 \\
\text { C }\end{array}$ & $\mathrm{TE}^{*}$ & $1.25 \pm 0.06^{\mathrm{BC}}$ & $\begin{array}{l}71.33 \pm 2.98 \\
\text { ABCD }\end{array}$ & $<0.1^{\mathrm{BC}}$ & $0.02 \pm 0.01 \mathrm{AB}$ & $39.6 \pm 2.9^{\mathrm{A}}$ & $13.9 \pm 1.1 \mathrm{DEF}$ & $774.0 \pm 50.4^{\mathrm{B}}$ \\
\hline 2 & Çiçek & Kocaeli & $19.6 \pm 0.1^{\text {в }}$ & $1.05 \pm 0.00^{B}$ & $0.18 \pm 0.00$ & $\begin{array}{c}1.37 \pm 0.10 \\
\mathrm{ABC}\end{array}$ & $56.31 \pm 2.59^{E}$ & $1.22 \pm 0.00 \mathrm{AB}$ & $0.03 \pm 0.02 \mathrm{AB}$ & $30.8 \pm 0.3^{\mathrm{BC}}$ & $17.1 \pm 0.6^{\mathrm{C}}$ & $621.3 \pm 28.5^{\mathrm{CDE}}$ \\
\hline 3 & Çiçek & Tekirdağ & $19.9 \pm 0.1^{\mathrm{A}}$ & $0.72 \pm 0.00^{\mathrm{D}}$ & $\mathrm{TE}$ & $\begin{array}{c}1.37 \pm 0.13 \\
\mathrm{ABC}\end{array}$ & $59.58 \pm 1.49^{\mathrm{DE}}$ & $<0.1^{\mathrm{C}}$ & $0.03 \pm 0.01 \mathrm{AB}$ & $34.9 \pm 0.5^{\mathrm{AB}}$ & $16.1 \pm 0.3^{\mathrm{CD}}$ & $552 \pm 29.9$ DEF \\
\hline 4 & Çiçek & Çankırı & $16.5 \pm 0.0^{\mathrm{F}}$ & $0.32 \pm 0.00^{\mathrm{F}}$ & $0.25 \pm 0.00$ & $1.27 \pm 0.10^{\mathrm{BC}}$ & $65.32 \pm 1.23 \mathrm{CDE}$ & $\begin{array}{l}0.59 \pm 0.01 \\
\mathrm{ABC}\end{array}$ & $0.02 \pm 0.01 \mathrm{AB}$ & $\begin{array}{l}23.3 \pm 0.3 \\
\mathrm{DEF}\end{array}$ & $14.4 \pm 0.7^{\mathrm{DE}}$ & $629.7 \pm 15.6^{\mathrm{CD}}$ \\
\hline 5 & Kestane & Kocaeli & $18.2 \pm 0.0^{\mathrm{C}}$ & $\begin{array}{l}1.97 \pm 0.01 \\
\text { A }\end{array}$ & $0.44 \pm 0.00$ & $1.49 \pm 0.05^{\mathrm{A}}$ & $78.58 \pm 3.23 \mathrm{AB}$ & $<0.1^{\mathrm{C}}$ & $0.01 \pm 0.00^{\text {В }}$ & $18.1 \pm 0.8^{\mathrm{F}}$ & $20.3 \pm 1.6^{\mathrm{B}}$ & $711 \pm 37.2^{\mathrm{BC}}$ \\
\hline 6 & Çiçek & Erzincan & $15.3 \pm 0.2^{\mathrm{G}}$ & $\begin{array}{l}0.22 \pm 0.00 \\
\mathrm{H}\end{array}$ & $1.38 \pm 0.00$ & $1.20 \pm 0.03^{\mathrm{C}}$ & $81.61 \pm 2.78^{\mathrm{A}}$ & $\begin{array}{l}0.65 \pm 0.47 \\
\mathrm{ABC}\end{array}$ & $0.03 \pm 0.00 \mathrm{AB}$ & $21.7 \pm 0.3^{\mathrm{EF}}$ & $\begin{array}{l}14.9 \pm 1.0 \\
\mathrm{CDE}\end{array}$ & $648.2 \pm 14.1$ ВCD \\
\hline 7 & Çiçek & Tokat & $16.3 \pm 0.1^{\mathrm{F}}$ & $0.39 \pm 0.00^{\mathrm{E}}$ & $\mathrm{TE}$ & $1.28 \pm 0.033^{\mathrm{BC}}$ & $72.42 \pm 1.22 \mathrm{ABC}$ & $<0.1^{\mathrm{C}}$ & $0.02 \pm 0.00^{\mathrm{B}}$ & $28.3 \pm 1.7^{\mathrm{CD}}$ & $25.4 \pm 0.9^{\mathrm{A}}$ & $715 \pm 13.2^{\mathrm{BC}}$ \\
\hline 8 & Çiçek & Tunceli & $13.9 \pm 0.0^{\mathrm{H}}$ & $0.18 \pm 0.00^{\mathrm{I}}$ & $3.43 \pm 1.07$ & $1.43 \pm 0.11 \mathrm{AB}$ & $77.64 \pm 4.83 \mathrm{AB}$ & $\begin{array}{l}0.19 \pm 0.01 \\
\mathrm{ABC}\end{array}$ & $0.02 \pm 0.01 \mathrm{AB}$ & $18.0 \pm 2.6^{\mathrm{F}}$ & $13.1 \pm 0.7^{\mathrm{EF}}$ & $434.8 \pm 25.4^{\mathrm{F}}$ \\
\hline 9 & Çiçek & $\begin{array}{l}\text { Gümüşhane- } \\
\text { Kelkit }\end{array}$ & $17.8 \pm 0.0^{\mathrm{D}}$ & $\underset{\mathrm{G}}{0.26} \pm 0.01$ & $1.36 \pm 0.00$ & $1.19 \pm 0.05^{\mathrm{C}}$ & $72.51 \pm 1.93 \mathrm{ABC}$ & $0.95 \pm 0.00^{\mathrm{A}}$ & $0.01 \pm 0.01^{\mathrm{B}}$ & $27.7 \pm 2.4^{\mathrm{CD}}$ & $9.0 \pm 0.0^{\mathrm{H}}$ & $681.4 \pm 33.6^{\mathrm{BCD}}$ \\
\hline 10 & Çiçek & Tokat & $19.3 \pm 0.3^{\text {В }}$ & $0.18 \pm 0.00^{\mathrm{I}}$ & $2.52 \pm 0.30$ & $1.26 \pm 0.02 \mathrm{BC}$ & $67.58 \pm 4.87$ ВСDЕ & $\begin{array}{l}0.52 \pm 0.01 \\
\mathrm{ABC}\end{array}$ & $0.02 \pm 0.01 \mathrm{AB}$ & $21.2 \pm 1.6^{\mathrm{EF}}$ & $11.6 \pm 0.9^{\mathrm{FG}}$ & $271 \pm 12.8^{\mathrm{G}}$ \\
\hline 11 & Çiçek & Erzurum & $17.3 \pm 0.1^{\mathrm{E}}$ & $0.31 \pm 0.00^{\mathrm{F}}$ & $0.46 \pm 0.00$ & $\begin{array}{l}1.33 \pm 0.00 \\
\text { ABC }\end{array}$ & $67.81 \pm 9.15^{\text {ВCDE }}$ & $<0.1^{\mathrm{C}}$ & $0.03 \pm 0.01 \mathrm{AB}$ & $\begin{array}{l}22.9 \pm 0.5 \\
\text { DEF }\end{array}$ & $21.6 \pm 0.2^{\text {В }}$ & $928.2 \pm 35.1^{\mathrm{A}}$ \\
\hline 12 & Çiçek & Kastamonu & $16.4 \pm 0.2^{\mathrm{F}}$ & $0.18 \pm 0.00^{\mathrm{I}}$ & $2.88 \pm 0.37$ & $1.20 \pm 0.01^{\mathrm{C}}$ & $69.19 \pm 1.10^{\mathrm{BCD}}$ & $\begin{array}{l}0.57 \pm 0.01 \\
\text { ABC }\end{array}$ & $0.06 \pm 0.05^{\mathrm{A}}$ & $\begin{array}{l}25.9 \pm 4.1 \\
\mathrm{CDE}\end{array}$ & $10.1 \pm 1.3^{\mathrm{GH}}$ & $485.1 \pm 45.4^{\mathrm{EF}}$ \\
\hline
\end{tabular}

*TE: Tespit Edilmedi 


\section{Sonuç}

Sonuç olarak balın fizikokimyasal özelliklerinin belirlenmesi balın kalitesi ve botanik kökeninin belirlenmesinde gerekli bir araçtır. TGK Bal Tebliğinde izin verilen değerler dikkate alındığında 12 adet çiçek bal numunesinden ikisinin elektrik iletkenliğinin yüksek olduğu, ikisinin glikoz ve fruktoz toplamının düşük olduğu, birinin fruktoz/glikoz oranının yüksek olduğu, birinin ise prolin miktarının düşük olduğu görülmüştür. Sadece 2 numaralı bal numunesinin iki parametreye birden uygun olmadiğı, elektriksel iletkenliğinin yüksek ve glikoz+fruktoz toplamının düşük olduğu belirlenmiştir. Geriye kalan yedi adet bal numunesinin fizikokimyasal özellikleri uygun bulunmuştur. Diğer taraftan, söz konusu fizikokimyasal özelliklerinden nem parametresinin balın coğrafi kökeninin belirlenmesinde kullanılabileceği öngörülmüş ancak bu çalışmada ispatlanamayan fakat literatüre göre mümkün olduğu görülen asitlik, HMF ve elektrik iletkenliği özellikleri için coğrafi bölgeler bazında çok sayıda numune ile çalışılması gerektiği sonucuna varılmıştır.

\section{Kaynakça}

AOAC (979.20). Official Methods of Analysis. Proline in honey. AOAC (977.20). Official Methods of Analysis. Separation of sugars in honey.

Aloglu, A. K., Harrington, P. de B., Sahin, S., Demir, C., \& Gunes, M. E. (2017). Chemical profiling of floral and chestnut honey using high-performance liquid chromatography-ultraviolet detection. Journal of Food Composition and Analysis, 62, 205-210. Doi:10.1016/j.jfca.2017.06.002

Belay, A., Solomon, W. K., Bultossa, G., Adgaba, N., \& Melaku, S. (2013). Physicochemical properties of the Harenna forest honey, Bale, Ethiopia. Food Chemistry, 141(4), 3386-3392. Doi:10.1016/j.foodchem.2013.06.035

Can, Z., Yildiz, O., Sahin, H., Akyuz Turumtay, E., Silici, S., \& Kolayli, S. (2015). An investigation of Turkish honeys: Their physico-chemical properties, antioxidant capacities and phenolic profiles. Food Chemistry, 180, 133-141. Doi: 10.1016/j.foodchem.2015.02.024

Erez, M, Karabacak, O, Kayci, L, Fidan, M, Kaya, Y . (2015). Characterization of Multifloral Honeys of Pervari Region with Different Properties. Türkiye Tarımsal Araştırmalar Dergisi , 2 (1) , 40-46 . DOI: 10.19159/tutad.20031

Fechner, D. C., Moresi, A. L., Díaz, J. D. R., Pellerano, R. G., \& Vazquez, F. A. (2016). Multivariate classification of honeys from Corrientes (Argentina) according to geographical origin based on physicochemical properties. Food Bioscience, 15, 49-54. Doi: 10.1016/j.fbio.2016.05.002

Habib, H. M., Al Meqbali, F. T., Kamal, H., Souka, U. D., \& Ibrahim, W. H. (2014). Physicochemical and biochemical properties of honeys from arid regions. Food Chemistry, 153, 35-43. Doi: 10.1016/j.foodchem.2013.12.048

Huang, L., Liu, H., Zhang, B., \& Wu, D. (n.d.). Application of Electronic Nose with Multivariate Analysis and Sensor
Selection for Botanical Origin Identification and Quality Determination of Honey. Doi:10.1007/s11947-014-1407-6

Karabagias, I. K., Badeka, A., Kontakos, S., Karabournioti, S., \& Kontominas, M. G. (2014). Characterisation and classification of Greek pine honeys according to their geographical origin based on volatiles, physicochemical parameters and chemometrics. Food Chemistry, 146, 548557. Doi: 10.1016/j.foodchem.2013.09.105

Karadal, F. (2012). Balın Kalite Nitelikleri, Beslenme ve Sağlık Açısından Önemi. Erciyes Univ J Vet Fac Derg, 9(3), $197-$ 209.

Kekecoglu, M., \& Rasgele, P.G. (2013). Physico-chemical analyses of Turkish honey samples: The assessment of quality of branded honeys available in the supermarkets and unbranded honeys from beekeepers. Agro FOOD Industry Hi Tech - January/February, 24(1), 38-41.

Kolayli, S., Can, Z., Yildiz, O., Sahin, H., \& Karaoglu, S. A. (2016). A comparative study of the antihyaluronidase, antiurease, antioxidant, antimicrobial and physicochemical properties of different unifloral degrees of chestnut ( Castanea sativa Mill. ) honeys. Journal of Enzyme Inhibition and Medicinal Chemistry, 31(sup3), 96-104. Doi:10.1080/14756366.2016.1209494

Küçük, M., Kolayli, S., Karaoğlu, Ş., Ulusoy, E., Baltaci, C., \& Candan, F. (2007). Biological activities and chemical composition of three honeys of different types from Anatolia. Food Chemistry, 100(2), 526-534. Doi:10.1016/j.foodchem.2005.10.010

Silici, S. (2018). Antioxidant And Physicochemical Properties of Chestnut Honeys From Turkey. Communications Faculty of Sciences University of Ankara Series C Biology, 27(2), 104114. Doi: 10.1501/commuc_0000000204

Silva, L. R., Videira, R., Monteiro, A. P., Valentão, P., \& Andrade, P. B. (2009). Honey from Luso region (Portugal): Physicochemical characteristics and mineral contents. Microchemical Journal, 93(1), 73-77. Doi:10.1016/j.microc.2009.05.005

Solayman, M., Islam, M. A., Paul, S., Ali, Y., Khalil, M. I., Alam, N., \& Gan, S. H. (2016). Physicochemical Properties, Minerals, Trace Elements, and Heavy Metals in Honey of Different Origins: A Comprehensive Review. Comprehensive Reviews in Food Science and Food Safety, 15(1), 219-233. Doi:10.1111/1541-4337.12182

Türk Gida Kodeksi (2020). Bal Tebliği 2020/7.

TS 13365 (2008). Bal-Su muhtevası tayini - Refraktometrik metot.

TS 3036 (2010). Bal.

TS 13360 (2008). Bal-Serbest asit muhtevasının tayini.

TS 13364 (2008). Bal-Diastaz aktivitesi tayini.

Turgay, Ö. (2009). Characteristic Properties of Kahramanmaras Honey Samples. KSÜ Doğa Bilimleri Dergisi, 12(2), 21-25. Alınmıştır: https://dergipark.org.tr/en/pub/ksudobil/issue/33395/371577 